\title{
A Study on the Initial Fracture Behavior of CF/GF Intra-Hybrid Woven Fabric Reinforced Composites
}

\author{
Zhilan Xu${ }^{1}$, Asami Nakai' ${ }^{2}$, Yuqiu Yang ${ }^{3}$, Hamada Hiroyuki ${ }^{1}$ \\ ${ }^{1}$ Kyoto Institute of Technology, Advanced Fibro-Science, Kyoto, Japan \\ ${ }^{2}$ Department of Mechanical Engineering, Gifu University, Gifu, Japan \\ ${ }^{3}$ Engineering Research Center of Technical Textiles, Ministry of Education, Donghua University, Shanghai, China \\ Email: *amy_yuqiu_yang@dhu.edu.cn
}

How to cite this paper: Xu, Z.L., Nakai, A., Yang, Y.Q. and Hiroyuki, H. (2018) A Study on the Initial Fracture Behavior of CF/GF Intra-Hybrid Woven Fabric Reinforced Composites. Open Journal of Composite Materials, 8, 11-27.

https://doi.org/10.4236/ojcm.2018.81002

Received: November 5, 2017

Accepted: December 23, 2017

Published: December 26, 2017

Copyright $\odot 2018$ by authors and Scientific Research Publishing Inc. This work is licensed under the Creative Commons Attribution International License (CC BY 4.0).

http://creativecommons.org/licenses/by/4.0/

\begin{abstract}
In this paper, woven fabrics of glass fiber/carbon fiber intra-hybrid in plain structure were used to fabricate fiber reinforced plastic (FRP) composite by hand lay-up method. The investigation on tensile property was carried out on specimens in 7 orientations including $0^{\circ} / 5^{\circ} / 15^{\circ} / 75^{\circ} / 85^{\circ} / 90^{\circ}$ in previous works. With the specimen parameters and experimental data, FEM model was built by the software of Marc. By combining the experimental results and finite element analysis, the modulus was simulated and calculated at the first stage. Then interfacial stress of the 0 degree and 90 degree was also calculated. By the initial fracture stress data from experiment as well as the simulation value of interfacial strength of 0 and 90 degree, the initial fracture stress of the off-axial specimens was calculated and predicted. The result shows that the interfacial strength of the glass fiber bundle is higher than that of the carbon fiber bundle in transverse direction. By using the interfacial strength and according to the Von Mises yielding criterion, the initial fracture stress was predicted, which can be a contribution to the design or predict of the material properties.
\end{abstract}

\section{Keywords}

Intra-Hybrid Woven Fabric Composite, FEM, Interfacial Strength, Initial Fracture

\section{Introduction}

Textile fabric is one of the important reinforcements widely used in manufacturing composites in variety of fields, such as automobile, construction and basic 
facilities. Among them, woven fabrics are probably the most commonly used form of textile composites in structural applications by far [1]. Woven fabrics generally consist of two sets of interlaced yarn components, known as warp and weft yarns according to the yarn orientation, and are manufactured principally by the multiple warp weaving method [2].

Currently, most of the pure and hybrid woven fabrics used in textile composites are simple 2D fundamental weaves, i.e., plain, twill and satin weaves [3], which are identified by the repeating patterns of the interlaced regions in warp and weft directions [4] [5] [6]. In particularly, hybrid woven fabric materials can be expected by combining different types of reinforcement into a polymer matrix [7], thus in which different properties can be achieved. Glass fiber, carbon fiber and aramid fiber are common reinforcement that used to fabricate hybrid composites [8] [9] [10]. GFRP (glass fiber reinforced plastic), characterized by high strength, low cost, low density, corrosion resistance easy to mold, is the base of modern composite industry. Therefore glass and carbon hybrid composite are largely applied for civilian use and also largely used in areas such as aerospace which are of high requirement in not only high mechanical property but also lightweight. On the other hand, CFRP (carbon fiber reinforced plastic) has higher specific modulus, specific strength compared with GFRP, but expensive. By introduce carbon fiber into glass fiber reinforced composite, the mechanical property can be improved further under controlled low cost due to the combining of each other's complementary advantages.

Due to the complicated microstructure of woven fabric, understanding of mechanical properties of textile fabric reinforced composite materials is of importance [11] [12] [13]. As previous work shows, initial fracture stress of composite reinforced by fabric with crisp structure usually happened as transverse crack in transverse fiber bundle [14] [15]. The interfacial property of the transverse fiber bundle plays an important role of the initial fracture property, which is difficult to understand or calculate from experimental data [16] [17].

For these reasons, there are a lot of papers on the research by numerical analysis method to understand the woven fabric reinforced composite [18] [19] [20] [21] [22]. In recent decades, many researchers have contributed to develop finite element analysis (FEA), which is a useful and versatile approach to understand and predict mechanical properties of textile composites [23] [24]. Mechanical behavior for textile composites by analysis method was proposed and the prediction of mechanical behavior was performed by Carvelli [25]. In his work, mechanical experiments were carried out at the first stage, and then monofilament textile geometries were examined and the tests were carried out on single fibers, to determine their tensile and friction properties. Mechanical behaviors of both axial and biaxial specimens were clarified. And then a numerical model was figured out to evaluate the mechanical properties of dry monofilament technical textiles and the model was calibrated according to the mechanical results. And this paper is also focused on the simulation of the initial fracture properties of the hybrid fabric reinforced composite. Siddiqui and Sun [26] developed a finite 
model to simulate and analyze the thermal conductivity and thermal resistance behavior of woven fabric and this model was validated by experimental results of the fabric. And one of the important results they found was that with the increase of the temperature and fiber volume fraction, effective thermal conductivity of fabric across the thickness also increases. Kim, D. H., Kim, H. G. and Kim, H. S [27] designed and manufactured hybrid glass/carbon composite bumper beam was via the design optimization process combined with the impact analysis. In the study of Cynthia Mitchell, Lisa Dangora, Christie Bielmeier and James Sherwood [28], investigations were pursued in an effort to understand the relationship between changes in the stiffness of plain-weave fabric-reinforced plates and the degree of in-plane shear within the fabric reinforcement. They identified that fabric shearing will result in several major changes within the reinforcement geometry that the reorientation of the fibers within the plane of the plate, the increase in plate thickness with increasing shear angle, and the change in the tow cross-sectional shape and orientation. Zako, M., Uetsuji, Y. and Kurashiki T. [29] investigated the damage behavior of FRP of which the reinforcement is woven fabric, and simulated by finite element analysis using an anisotropic damage model based on damage mechanics. By this model, inner damage of fiber bundle was simulated and revealed. It was turned out that good agreement between the analytical and experimental results, which is important of the utility in evaluating the damage mechanism of fabric reinforced composite. Boisse, P. et al. [30] [31] built a woven fabric model and stressed the importance of in-plane shear rigidity in finite element analyses of woven fabric composite preforming and proposed in-plane shear for the simulation of fabric forming. Le Page et al. developed two dimensional plane strain finite element models and simulate some of the different local fabric geometries which influence the damage development seen in woven fabric laminates as a function of number of reinforcing layers [32]. MA Badie, E Mahdi and AMS Hamouda [33] adopted Finite element analysis to predict the fatigue life of composite drive shaft using linear dynamic analysis for different stacking sequence. Tabiei A. and Jiang Y. [34] made an effort to develop simple, yet generalized, model which considers the two-dimensional extent of woven fabric and to have an interface with nonlinear finite element codes. Ichihashi and Hamada et al. [35] proposed an FEA model for evaluating mechanical properties of single ply of woven fabric composite.

As stated above, understanding of mechanical properties of textile fabric reinforced composite materials is of great importance for the complicated microstructure of woven fabric. And due to the reason that it is difficult to observe and obtain the interfacial property of the transverse fiber bundle from experimental data, which plays an important role of the initial fracture property, numerical analysis method is considered to be adopted to understand the initial fracture behavior of woven fabric reinforced composite.

In this paper, composites fabricated with woven fabric of glass/carbon intra-hybrid in plain structure by hand lay-up method were adopted. Investigation on the tensile property was carried out on specimens in 7 orientations including 
$0^{\circ} / 5^{\circ} / 15^{\circ} / 75^{\circ} / 85^{\circ} / 90^{\circ}$ in previous works. With the specimen parameters and experimental data, FEM model was built by software Marc. At the first stage, tensile moduli were calculated and compared with experimental results. On the premise of the validity of the simulation value of tensile modulus, interfacial stresses of the transverse elements in 0 degree and 90 degree models were also calculated. Among those, the maximum was regarded as the interfacial strength of the transverse fiber bundles. By the experimental data of initial fracture stress as well as the simulation value of interfacial strength of 0 and 90 degree, the initial fracture stress as well as the distribution of interface elements of the off-axial specimens were calculated and predicted.

\section{Background}

\subsection{Experiments}

In previous work [18], mechanical properties of $\mathrm{CF} / \mathrm{GF}$ in different degree have been tested and discussed. Carbon fiber /glass fiber intra-hybrid woven fabric, in which carbon fiber bundle (Toray Industries, Inc. T700SC-12000, 1600 Tex) fabricated as weft yarn and glass fiber bundle (Nitto Boseki Co., Ltd RS 110QL-521), 1150 Tex as warp yarn, was used as reinforcement. The hybrid woven cloth is in plain structure as the photo and the fabric structure pattern. The gram per square meter (GSM) of the woven fabric is turned out to be $604 \mathrm{~g} / \mathrm{m}^{2}$, within which the GSM of glass fiber bundles is $305 \mathrm{~g} / \mathrm{m}^{2}$ while carbon fiber bundles is $209 \mathrm{~g} / \mathrm{m}^{2}$. Vinyl ester resin (R-806B: Showa Denko K.K.) was adopted as matrix. The detail mechanical properties of the fibers and resin are listed in Table 1. The intra CF/GF woven fabric reinforced composite was manufactured by hand lay-up molding method. The laminated constitution included 2 plies of the CF/GF hybrid woven cloth. After the molding and post cure, the composite board was cut into the size of $200 \mathrm{~mm} \times 20 \mathrm{~mm}$ (length $\times$ width) according to the ASTM D3039. Thickness of the specimen is about $1 \mathrm{~mm}$. In this research, specimens were arranged and cut into 7 different orientation angles $\left(5^{\circ} / 15^{\circ} / 45^{\circ} /\right.$ $75^{\circ} / 85^{\circ} / 90^{\circ}$ ), among which the initial fracture properties of 0 degree and the 90 degree was analyzed and discussed particularly.

Tensile test was carried out on an Instron universal testing machine at the speed of $1 \mathrm{~mm} / \mathrm{min}$ and the test room temperature is $22^{\circ} \mathrm{C}$. Strain gauges were used to measure the tensile strain. 3 specimens have been repeated for each type. Max stress, modulus and the stress-strain curves of 7 types of specimens were

Table 1. Mechanical properties of fibers and matrix.

\begin{tabular}{ccccc}
\hline & $\begin{array}{c}\text { Tensile strength } \\
(\mathrm{MPa})\end{array}$ & $\begin{array}{c}\text { Elastic modulus } \\
(\mathrm{GPa})\end{array}$ & Elongation $(\%)$ & Density $\left(\mathrm{g} / \mathrm{cm}^{3}\right)$ \\
\hline Glass & $2300-2400$ & $70-76$ & $3-3.2$ & $2.55-2.62$ \\
Carbon & 4900 & 230 & 2.1 & 1.8 \\
Vinyl Ester & $69-89$ & 3 & $6.0-8.0$ & $1.2\left(25^{\circ} \mathrm{C}\right)$ \\
\hline
\end{tabular}


obtained and analyzed. Knee point stress was obtained by AE device during the tensile test. In order to investigate the initial fracture behavior of the intra $\mathrm{CF} / \mathrm{GF}$ woven composite, especially for the difference between the GF and CF, video was shot during the tensile test.

\subsection{Tensile Test Results [18]}

The detail of the result of the tensile test in previous work is summarized and shown in Table 2 [18]. It can be seen that as the orientation angle increasing from 0 degree to 45 degree, the tensile elastic modulus decreased firstly, while from 45 degree to 90 degree, a tendency of dramatic increase, in details the 0 degree specimen showed the lowest modulus of $12 \mathrm{GPa}$ while the 90 degree specimen the highest modulus of $50.5 \mathrm{GPa}$. Regarding to the strength, it is revealing that the trend of the tensile strength of the 7 types of specimens is similar with that of the elastic modulus. While be different with modulus, the lowest strength is 45 degree specimen. As referred to the initial fracture stress in previous work [18], from 0 degree to 45 degree it is almost stable at about $35 \mathrm{MPa}$. However, from 45 degree to 90 degree, it increased significantly, which is considered due to the CF fiber orientation. In summary, the orientation angles do have effect on the mechanical properties of the specimen because of both of the woven structure of the reinforcement and CF/GF hybrid architecture [18].

Besides, in previous work [18], the initial fracture of the fiber bundles were observed by stretching the specimen to pre-set load and stopping it at knee point generated stage, then carrying out observation by optical microscope. The transverse crack reflected the interfacial property within the fiber bundles. The optical observation result from previous work [18] was summarized in Figure 1. As it is shown in Figure 1, the transverse crack began to appear in fiber bundles during the initial fracture period. And more transverse crack expanded within the fiber bundle with the tensile load increasing. As the fracture sketch of the 0 degree specimen illustrated in Figure 1(a), the presence of the crack showed within the carbon fiber bundles after the tensile test [18]. In the observation of the 90 degree specimen, transverse crack can be also observed at the initial fracture

Table 2. Summary of the tensile test results [8].

\begin{tabular}{ccccc}
\hline & $\begin{array}{c}\text { Tensile modulus } \\
(\mathrm{GPa})\end{array}$ & $\begin{array}{c}\text { Tensile Strength } \\
(\mathrm{MPa})\end{array}$ & $\begin{array}{c}\text { Initial fracture stress } \\
(\mathrm{MPa})\end{array}$ & $\begin{array}{c}\text { Initial fracture strain } \\
\text { Rate }(\%)\end{array}$ \\
0 & 23.2 & 351.4 & 32.9 & 3.7 \\
5 & 21.1 & 278.5 & 39.3 & 3.2 \\
15 & 18.5 & 157.4 & 38.1 & 4.3 \\
45 & 12.0 & 112.6 & 32.6 & 5.5 \\
75 & 40.5 & 225.2 & 87.9 & 5.0 \\
85 & 49.2 & 494.1 & 198.3 & 4.3 \\
90 & 50.5 & 780.6 & 184.2 & 4.8 \\
\hline
\end{tabular}




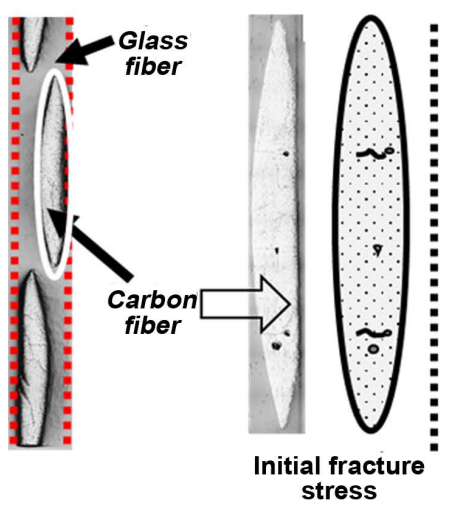

(a)

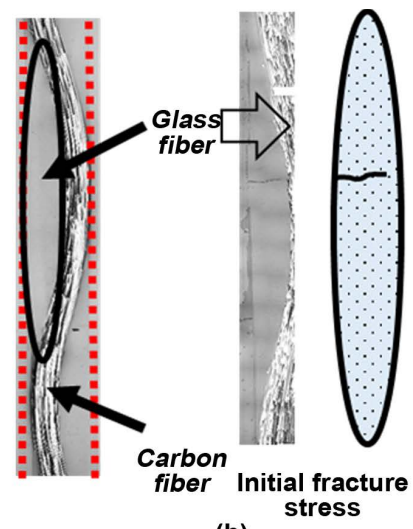

(b)

Figure 1. Optical observation of initial fracture cracks in transverse fiber bundles. (a) Cracks in carbon fiber bundles; (b) Cracks in glass fiber bundles [18].

stage. More transverse crack appeared with the increase of the tensile load. And in previous work [18], it is also suggested a poor interfacial property within the carbon fiber bundle when the resin is vinyl ester. Compared with the crack within the glass fiber bundle, the fracture seemed to be fierce in the carbon fiber bundles in transverse fiber bundle direction.

\section{Models}

\subsection{Geometric Parameters}

In previous works [18] [35], Ichihashi and Hamada et al. proposed an FEA model for evaluating mechanical properties of single ply of woven fabric composite. In this model, interfacial properties were considered, and woven fabric was modelled by using a pair of parallel beam elements expressing a fiber bundle and an interphase element between the two elements. In this research, finite element models were also developed with the consideration of the actual dimension of the woven structure. Furthermore, in order to investigate the properties within the transverse fiber bundles, transvers fiber elements were designed to improve the previous model.

To build up the model by Marc, parameters of the weft and warp yearns are necessary. Specimen was cut and buried in resin to obtain the exact dimension of the weft fiber bundle and warp fiber bundle. After polishing, optical observation was carried out to get the geometric parameters.

Four types of parameters including the major axis, minor axis, distance between fiber bundles (d0) as well as the fiber bundle area as Figure 2 shows, were measured. It can be seen from Table 3 that the aspect of the major axis and the minor axis of fiber bundle is respectively big and the fiber bundle is close to an oval shape. For this reason, the cross-section of the fiber bundle was divided into two rectangles, and represented by two elements. Interfacial elements are designed between these two lines to join them into one fiber bundle. According to the element type used in this model, the cross-section area and the second moments 
were calculated by the four parameters and inputted as geometric parameters. Then a finite element model is developed with the consideration of the above factors. The model is illustrated in Figure 3 as an example. The woven fabric structure was simplified and divided into several types including yarn elements, interphase elements and resin element. And the detail element structure of woven fabric model is shown in Figure 4.

Table 3. Geometric parameters of hybrid composites.

\begin{tabular}{ccccc}
\hline & Major axis $(\mathrm{mm})$ & Minor axis $(\mathrm{mm})$ & Area $\left(\mathrm{mm}^{2}\right)$ & $\begin{array}{c}\text { Distance between fiber } \\
\text { bundle }(\mathrm{mm})\end{array}$ \\
Warp & 4.170 & 0.237 & 0.608 & 4.259 \\
Weft & 4.056 & 0.256 & 0.747 & 4.244 \\
\hline
\end{tabular}
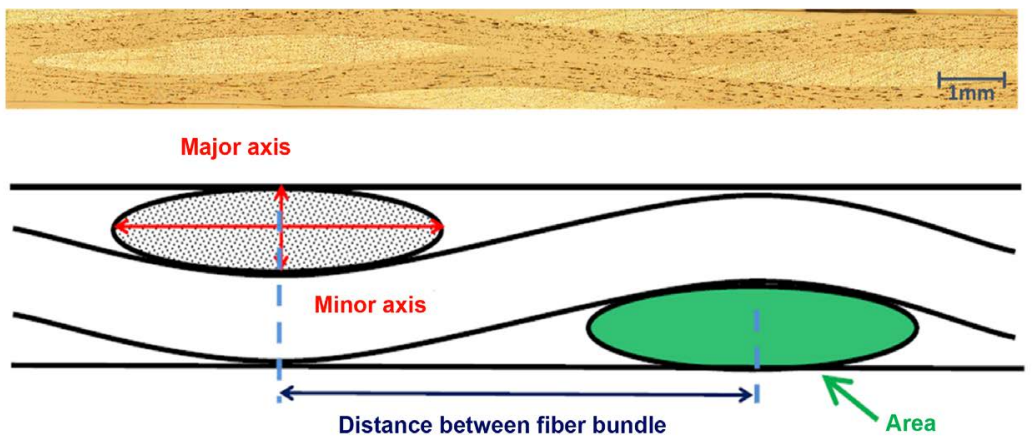

Figure 2. Optical observation of geometric parameter.

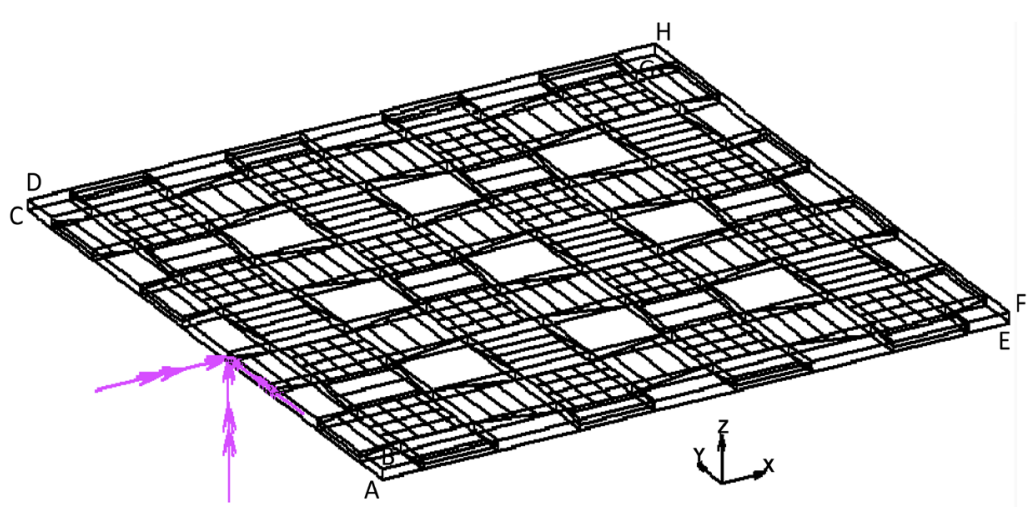

Figure 3. FEM model of carbon-glass hybrid fabric.

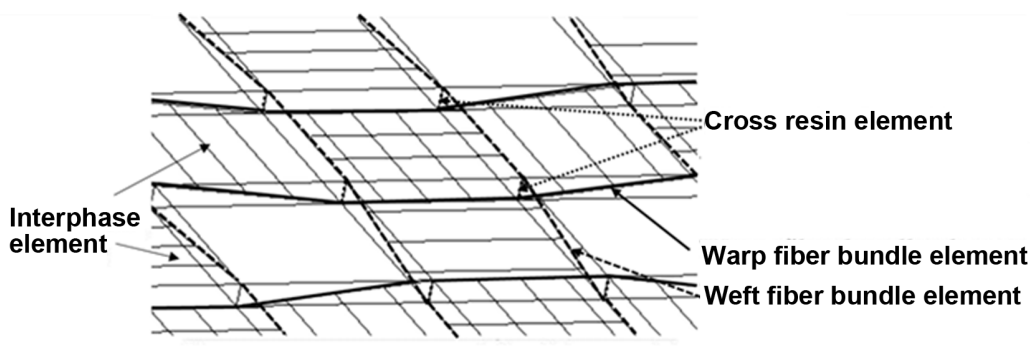

Figure 4. Element structure of woven fabric model. 


\subsection{Mechanical Parameters}

After the model was built, mechanical properties of the weft and warp yeans were identified. For mechanical parameters, $V_{f}$ (volume fraction of reinforce fiber), modulus, of glass fiber bundle and carbon fiber bundle are necessary. Since the elastic modulus of a fiber bundle in matrix is different with its catalogue elastic modulus value, it need to be recalculated Here, the $V_{f}$ of the fiber bundle is calculated by the number and the area of the filaments and the cross section area of the fiber bundle by Equation (1) as follows:

$$
V_{f}=A \frac{N}{S}
$$

Here $A$ is the area of the fiber bundle cross-section; $N$ is the number of filaments in one fibber bundle; $S$ is the sum of the fibers in cross section area.

These three values are measured and obtained by the optical observation of the fiber bundle cross-section. After the $V_{f}$ is obtained, with the elastic modulus of the fiber and the resin, the modulus of the fiber bundle is calculated by the composite rule. Young's modulus and the Poisson ratio are two necessary parameters for the mechanical property of fiber bundles.

\subsection{Boundary Conditions}

Models are controlled by displacement in this study. For on-axis model of 0 degree and 90 degree, unit displacement $1 \mathrm{~mm}$ was applied to the model along the load direction $x$ and $y$ axial direction separately. However, there is difference between the axis and off axis models, for the boundary conditions. Take the 5 degree for examples, for on-axis model of 0 degree, unit displacement $1 \mathrm{~mm}$ was applied to the model along the load direction. While for off-axis model of 5 degree model, it was considered to apply the displacement in 5 degree orientation, instead of build a model with off-axis fiber bundles. Then the displacement along 5 degree was divided into $\mathrm{x}$ and $\mathrm{y}$ two directions as it is shown in Figure 5. For the 5 degree model, in $\mathrm{x}$ direction was applied by $0.996 \mathrm{~mm}$ displacement and the y direction was applied by $0.087 \mathrm{~mm}$ direction, to ensure the displacement along the 5 degree. The original and deformed models of 5 degree were taken as an example shown in Figure 6. It can be seen that there was displacement deform in both $\mathrm{x}$ and $\mathrm{y}$ direction.

\section{Simulation Results}

Based on the results of the geometric parameter and mechanical property, model of both 0 degree and 90 degree were built at first, elastic modulus and the max interfacial fracture stress was calculated and compared.

\subsection{Tensile Modulus}

In order to analysis the mechanism of the initial fracture stage, the simulation was carried out within the elastic area. For on-axis model of 0 degree and 90 degree, unit displacement $1 \mathrm{~mm}$ was applied to the model along the load direction 


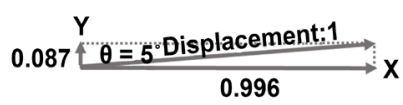

Figure 5. Displacement boundary conditions of 5 degree.

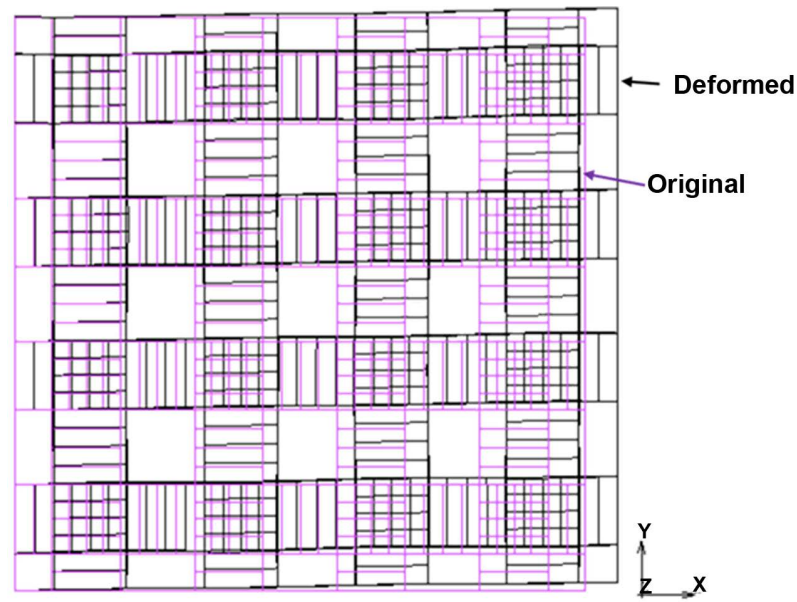

Figure 6. Original and deformed model of 5 degree.

Table 4. Tensile Modulus simulation result of on-axis.

\begin{tabular}{cccc}
\hline Degree & Experimental tensile modulus (GPa) & Simulation tensile modulus (GPa) & Error (\%) \\
\hline 0 & 23.2 & 22.3 & $4 \%$ \\
90 & 50.5 & 48.8 & $3 \%$ \\
\hline
\end{tabular}

Table 5. Modulus simulation result of off-axis.

\begin{tabular}{cccc}
\hline Degree & Experimental tensile modulus (GPa) & Simulation tensile modulus (GPa) & Error (\%) \\
\hline 5 & 21.1 & 22.2 & $5 \%$ \\
85 & 49.2 & 48.3 & $2 \%$ \\
\hline
\end{tabular}

$x$ and $y$ axial direction separately. The simulation modulus was calculated by summarizing the total stress of all the nodes along the applied force direction first and then dividing by the corresponding cross-section area. The analysis result of modulus by FEM model and compared with the result from experiment as shown in Table 4. It can be known that the tensile modulus deviation is below $5 \%$.

Tensile modulus was also calculated for off-axis cases. The analysis result of tensile modulus by FEM model and compared with the result from experiment as shown in Table 5. It can be known that the modulus deviation is below $5 \%$ for 5 degree and 85 degree.

\subsection{Interfacial Strength}

As load increased during the experiment, initial fracture happened within the transverse fiber bundle of the specimen. It is known from the previous work that initial fracture in plain woven fabric composite was confirmed as transverse 
crack in weft fiber bundle. For the 0 degree and 90 degree, the axial tensile stress was clarified as the dominate stress, which suggest that the tensile force is the main fracture reason for the interfacial element. In order to get the interfacial strength in transverse fiber bundle, the principal stress of the interfacial elements was calculated by dividing the axial force of the interphase element by the cross section area because the shear stress. Combining with the initial fracture stress from the experiment and the initial fracture from the model, interfacial strength of the glass fiber bundle and carbon fiber bundle as transverse direction was calculated by the Equation (2).

$$
\sigma_{\text {interfacial }}=\frac{\sigma_{\text {initial }}}{\sigma^{\prime}} \cdot \sigma_{\text {interfacial }}^{\prime}
$$

Here $\sigma_{\text {initial }}$ is initial fracture stress from experimental data; $\sigma_{\text {initial }}^{\prime}$ is calculated value of initial fracture stress from model; $\sigma_{\text {interfacial }}$ is the simulation value of interfacial strength in transverse fiber bundle; $\sigma_{\text {interfacial }}^{\prime}$ is calculated value of interfacial strength from on axis models.

As it is known, the yield point stress can be usually measured by tensile test of the unidirectional composite. For axial reinforcement like woven fabric, due to the complex load situation, it is difficult to judge the yield point because the shear stress might be involved in the meantime. The von Mises yield criterion is used to solve the yield point problem of multi-axial stress situation involved with more than one stress component. The von Mises yield criterion suggests that the yielding of material begins when the second deviatoric stress invariant reaches a critical value. Among the interfacial elements, not only the tensile stress along the elements' axial direction, but also the shear stress along the vertical direction were clarified.

The Von Mises stress of the interfacial elements was calculated according to Equation (3):

$$
\sigma_{i, \text { interfacial }}=\sqrt{\frac{\begin{array}{l}
\left\{\left(\sigma_{x x}-\sigma_{y y}\right)^{2}+\left(\sigma_{y y}-\sigma_{z z}\right)^{2}+\left(\sigma_{z z}-\sigma_{x x}\right)^{2}\right. \\
\left.+3\left(\sigma_{x y}^{2}+\sigma_{x z}^{2}+\sigma_{y x}^{2}+\sigma_{y z}^{2}+\sigma_{z x}^{2}+\sigma_{z y}^{2}\right)\right\}
\end{array}}{2}}
$$

Here $\sigma_{x x}, \sigma_{y y}$ and $\sigma_{z z}$ are the axial tensile stress along $x, y$ and $z$ direction, respectively; $\sigma_{x y} \sigma_{x z} \sigma_{y x}, \sigma_{y z}, \sigma_{z x}$ and $\sigma_{z y}$ are the shear stress along $x y, x Z, y X, y z, Z X$ and $z y$ direction, respectively

The result of both max principal stress and the Von Mises stress of the interfacial elements is shown in Table 6 for 0 degree and 90 degree. From this table, it can be seen that the max principal stress is almost same with the Von Mises stress.

And for glass/carbon hybrid, the transverse fiber bundles' interfacial strength of the 90 degree (transverse fiber bundle is glass fiber) is much higher than that of the 0 degree (transverse fiber bundle is glass fiber), which shows that the interfacial strength property of glass fiber bundle is better than the carbon fiber bundle in transvers direction. According to previous works, if one is to calculate 
Table 6. Interfacial strength and initial fracture stress simulation result.

\begin{tabular}{ccccccc}
\hline Degree & $\begin{array}{c}\text { Initial } \\
\text { fracture } \\
\text { stress }(\mathrm{MPa})\end{array}$ & $\begin{array}{c}\text { Max axial } \\
\text { stress } \\
(\mathrm{MPa})\end{array}$ & $\begin{array}{c}\text { Von Mises } \\
(\mathrm{MPa})\end{array}$ & $\begin{array}{c}\text { Simulation } \\
\text { interfacial } \\
\text { Strength (MPa) }\end{array}$ & $\begin{array}{c}\text { Simulation } \\
\text { initial } \\
\text { fracture (MPa) }\end{array}$ & Error (\%) \\
\hline 0 & 32.9 & 356.4 & 357.6 & 11.0 (carbon) & - & - \\
90 & 184.2 & 438.9 & 440.5 & 28.1 (glass) & - & - \\
5 & 39.3 & 354.6 & 355.9 & - & 40.4 & $3 \%$ \\
85 & 198.3 & 420.2 & 421.5 & - & 189.9 & $4 \%$ \\
\hline
\end{tabular}

the interfacial fracture stress, the stress distribution at a fiber-matrix interface subjected to loading must be known. Thus, in order to find out where the max interfacial stress happened, interfacial stress value of every transverse fiber bundles were collect from both the principal stress and Von Mises stress. And the results show that for both the principal stress and Von Mises stress, the max value happened at the same position.

Where the max value of the Von Mises stress of 0/5/85/90 degree happened is shown in Figure 7. The Von Mises stress distribution of every interphase element of the model was shown in Figure 7(b). In Figure 7(a), the place where the max element stress value happened in cases of $0 / 5$ degree was marked with bold black line. It can be seen that, the max interfacial stress happen within the transverse fiber bundle and between two warp fiber bundles.

With the interfacial strength from the on-axial models and the Von Mises stress from the off-axial, the initial fracture value can be predicted by Equation (4) as follows:

$$
\sigma_{i, \text { initial }}=\frac{\sigma_{\text {interfacial }}}{\sigma_{i, \text { interfacial }}^{\prime}} \cdot \sigma_{i, \text { initial }}^{\prime}
$$

Here $\sigma_{i, \text { initial }}$ is the simulation value of initial fracture stress of off-axial specimen; $\sigma_{i, \text { inital }}^{\prime}$ is calculated value of the initial fracture stress from off-axial model; $\sigma_{\text {interfacial }}$ is the simulation value of interfacial strength in transverse fiber bundle; $\sigma_{i, \text { interfacial }}^{\prime}$ is calculated value of the Max Von Mises stress of interfacial elements from off axis models

The analysis result of interfacial strength and the initial fracture stress by FEM model and compared with the result from experiment is also shown in Table 6. It is revealed by Table 6 that the simulation value of the initial fracture agreed well with the experimental result with a difference below $5 \%$.

\subsection{Shear Stress of Beam Elements}

In this study, 3D solid beam element was adopted. As it is referred to the local coordinate of the beam element, $\mathrm{x}$ direction and $\mathrm{y}$ direction is perpendicular in cross section plane and $\mathrm{z}$ direction is along the beam longitude axial direction as illustrating in Figure 8. Shear stress in local coordinate was calculated and collected. The distribution of shear stress of $\mathrm{x}$ direction and $\mathrm{y}$ direction are shown in Figure 9(a) and Figure 9(b) separately. $t$ can be seen that the shear stress 


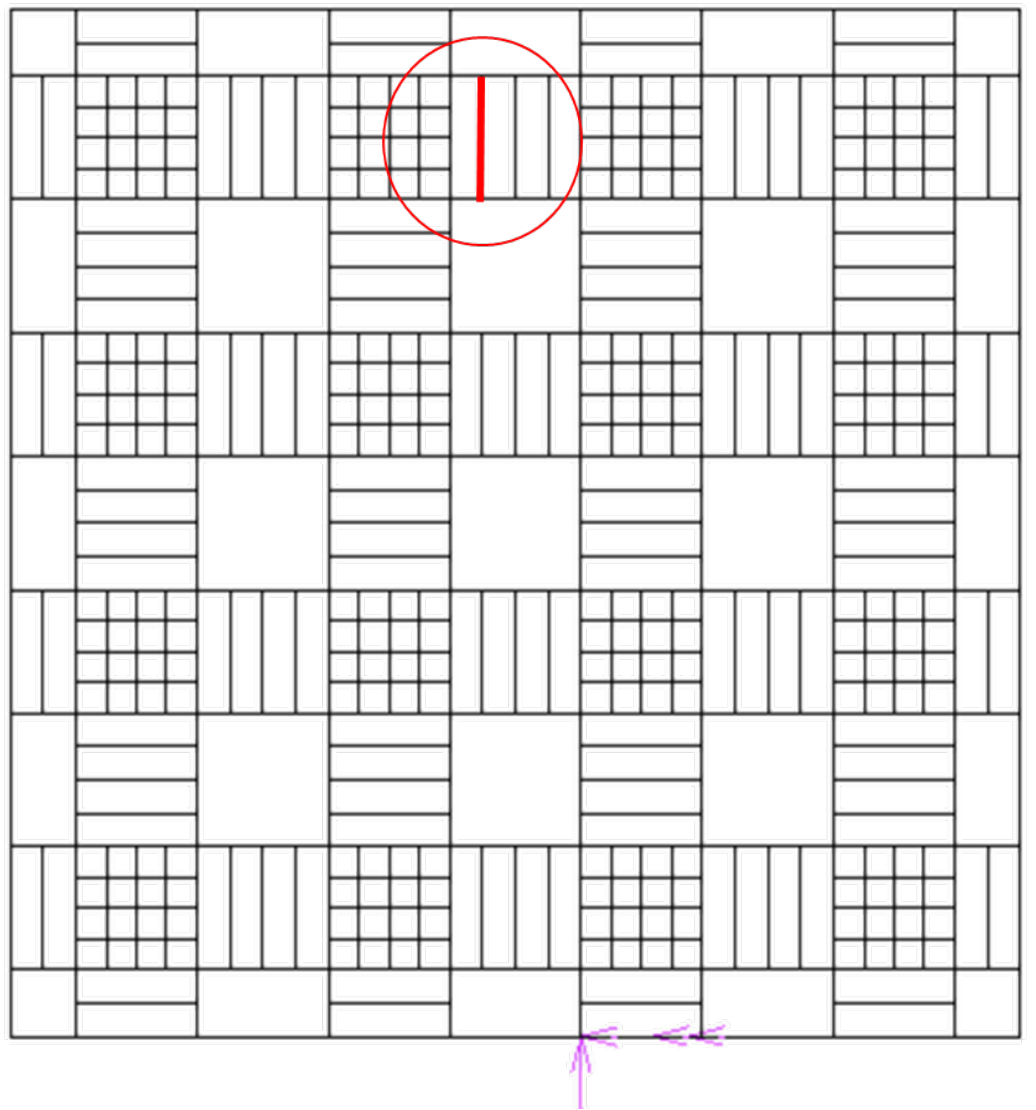

(a)

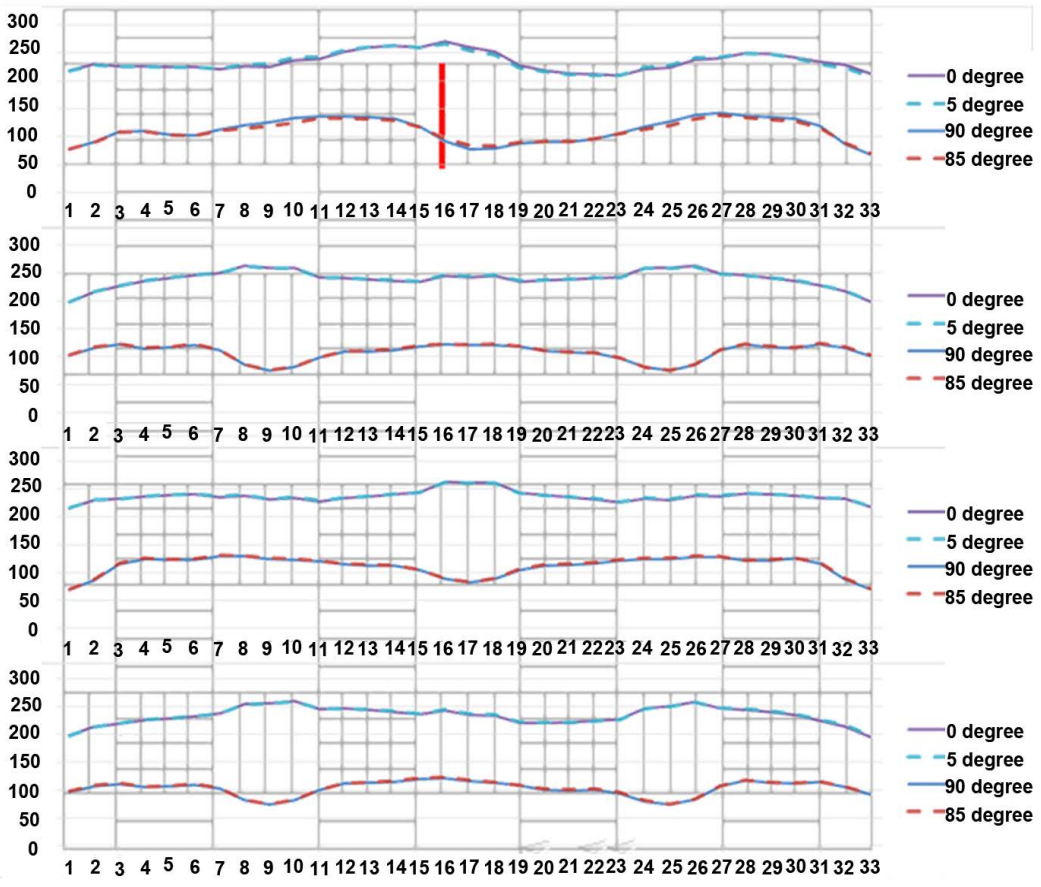

(b)

Figure 7. Interfacial strength simulation results of 0/5/85/90 degree. (a) Interfacial strength position by Von Mises stress of 0/5 degree; (b) The Von Mises stress distribution of interface elements. 


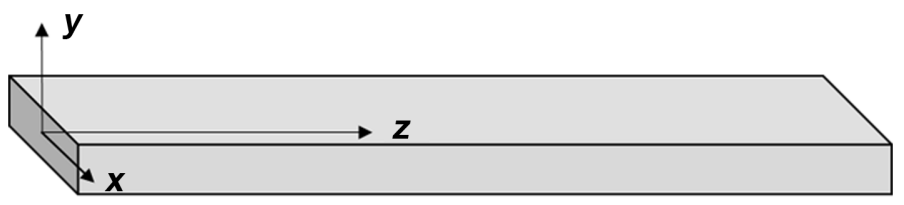

Figure 8. Local coordinate of beam element.

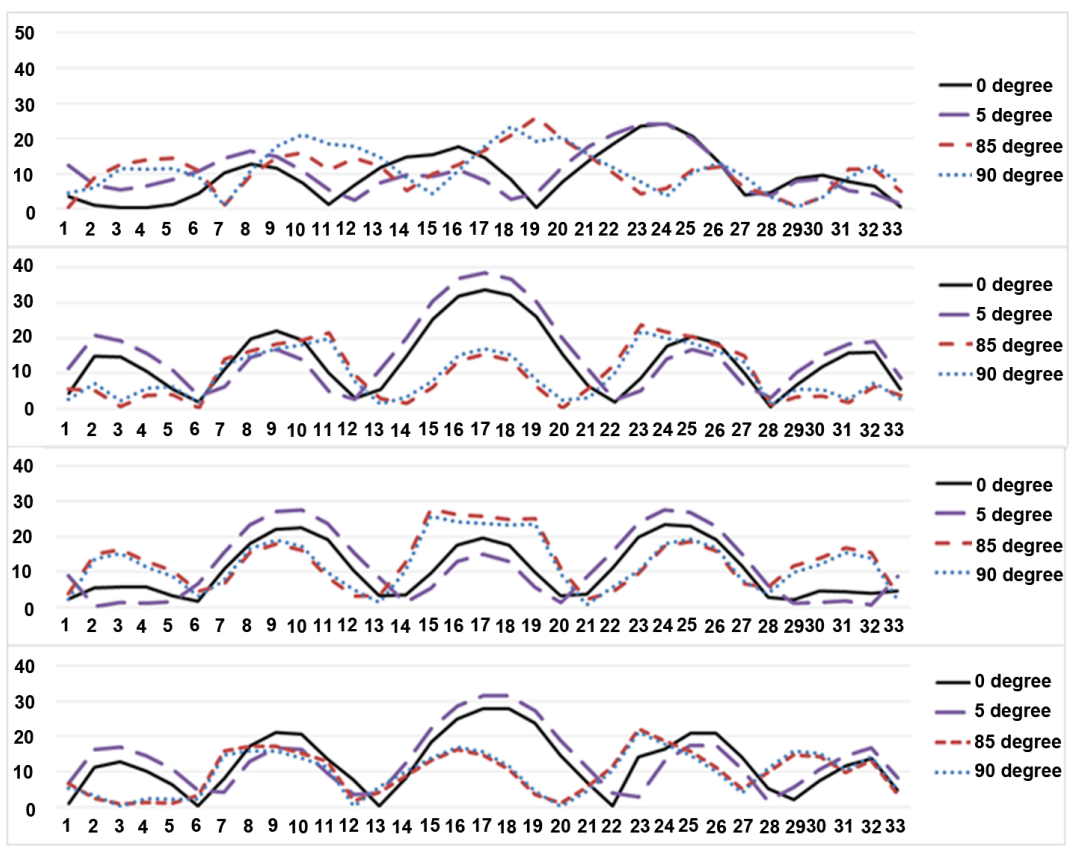

(a)

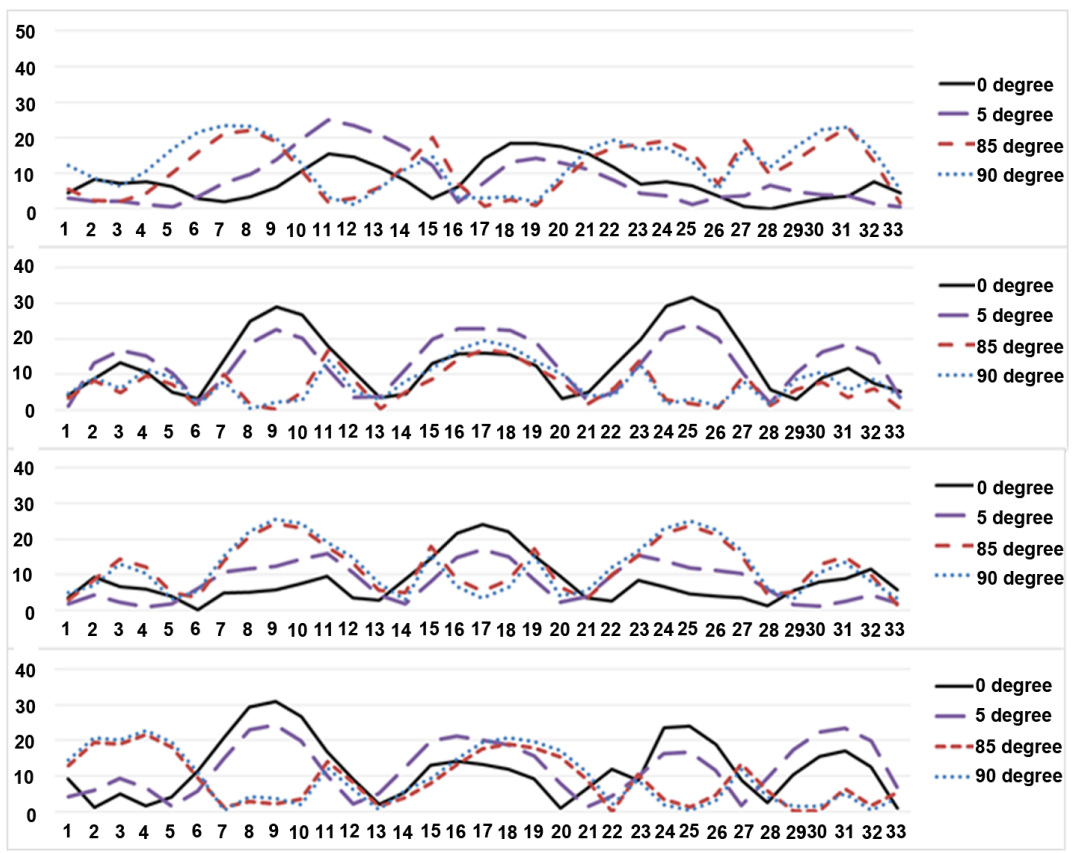

(b)

Figure 9. Shear stress distribution in local coordinate of 0/5/85/90 degree. (a) Shear stress distribution in $\mathrm{x}$ direction; (b) Shear stress distribution in $\mathrm{y}$ direction. 
Table 7. Max value of stress in interface elements.

\begin{tabular}{ccccc}
\hline & $\begin{array}{c}\text { Max axial stress } \\
(\mathrm{MPa})\end{array}$ & Shear stress $(\mathrm{MPa})$ & $\begin{array}{c}\text { Von Mises equivalent } \\
\text { stress }(\mathrm{MPa})\end{array}$ & $\begin{array}{c}\text { Max Principal } \\
\text { stress (MPa) }\end{array}$ \\
\hline 0 & $270.4(-)$ & $33.8(-)$ & $271.4(-)$ & $282.0(-)$ \\
5 & $266.5(-1 \%)$ & $38.6(14 \%)$ & $266.9(-2 \%)$ & $283.0(-0 \%)$ \\
85 & $138.8(-1 \%)$ & $33.0(4 \%)$ & $140.9(-3 \%)$ & $149.3(-3 \%)$ \\
90 & $143.5(-)$ & $31.9(-)$ & $145.5(-)$ & $154.6(-)$ \\
\hline
\end{tabular}

values in local coordinate of the beam elements are showing a waveform changes with relatively high values between two warp fiber bundles and low value in the cross area of warp and weft fiber bundles. Besides, according to Table 7, the max values of axial stress, shear stress, Von Mises equivalent stress and principal stress of all the interphase elements were listed, with the deviation percentage to the on-axis cases. There is no big difference between the max values of axial stress, Von Mises equivalent stress and principal stress. It can be consider that there is an increasing tendency of the shear stress with the off-axis degree increasing, which reveals that with the off-axis degree increased, the transverse fiber bundles were subjected to higher shear stress.

\section{Conclusion}

In order to get a good knowledge of the mechanical properties of woven fabric reinforced composites, numerical analysis method is considered to be a valid method to understand the initial fracture behavior for the complicated microstructure of woven fabric reinforced composite. In this paper, FEM model of woven structure was built up, then tensile modulus and the interfacial properties of the transverse fiber bundle were simulated and compared. From on-axial models, the interfacial strength of the glass fiber bundle and carbon fiber bundle was calculated. The results show that the interfacial strength of the glass fiber bundle is higher than that of the carbon fiber bundle in transverse direction. By using the interfacial strength, the initial fracture stress of off-axis cases was predicted. And the distribution of the axial stress, shear stress, Von Mises equivalent stress and principal stress was calculated and illustrated. It is clarified that in off-axis cases, shear stress in interphase elements is higher than on-axis cases, which showed that the transverse fiber bundles were subjected to higher shear stress. Through model built by Marc and analysis by FEM, the modulus and the initial fracture stress simulation can be achieved, which can be a contribution to the design or predict of the material properties.

\section{References}

[1] Laroche, D. and Vu-Khanh, T. (1994) Forming of Woven Fabric Composites. Journal of Composite Materials, 28, 1825-1839.

https://doi.org/10.1177/002199839402801805 
[2] Demircan, O. (2016) Initial and Final Fracture Behaviors of Woven Fabric Composites. Science and Engineering of Composite Materials, 23, 161-177.

https://doi.org/10.1515/secm-2014-0178

[3] Dai, S., Cunningham, P., Marshall, S. and Silva, C. (2015) Influence of Fibre Architecture on the Tensile, Compressive and Flexural Behaviour of 3D Woven Composites. Composites Part A: Applied Science and Manufacturing, 69, 195-207. https://doi.org/10.1016/j.compositesa.2014.11.012

[4] Zhang, Y. and Harding, J. (1990) A Numerical Micromechanics Analysis of the Mechanical Properties of a Plain Weave Composite. Computers \& Structures, 36, 839-844. https://doi.org/10.1016/0045-7949(90)90154-T

[5] Stegschuster, G., Pingkarawat, K., Wendland, B. and Mouritz, A. (2016) Experimental Determination of the Mode I Delamination Fracture and Fatigue Properties of Thin 3D Woven Composites. Composites Part A: Applied Science and Manufacturing, 84, 308-315. https://doi.org/10.1016/j.compositesa.2016.02.008

[6] Vandeurzen, P., Ivens, J. and Verpoest, I. (1996) A Three-Dimensional Micromechanical Analysis of Woven-Fabric Composites: I. Geometric Analysis. Composites Science and Technology, 56, 1303-1315. https://doi.org/10.1016/S0266-3538(96)00092-9

[7] John, M.J. and Thomas, S. (2008) Biofibres and Biocomposites. Carbohydrate Polymers, 71, 343-364. https://doi.org/10.1016/j.carbpol.2007.05.040

[8] Ishikawa, T. and Chou, T.-W. (1983) One-Dimensional Micromechanical Analysis of Woven Fabric Composites. AIAA Journal, 21, 1714-1721.

https://doi.org/10.2514/3.8314

[9] Miller, E. (1969) Textiles: Properties and Behaviour. Theatre Arts Books.

[10] Naik, N., Shembekar, P. and Hosur, M. (1991) Failure Behavior of Woven Fabric Composites. Journal of Composites, Technology and Research, 13, 107-116. https://doi.org/10.1520/CTR10214J

[11] Xie, J., Yao, L., Xu, F., Li, Y., Shan, Z., Hui, D., et al. (2014) Fabrication and Characterization of Three-Dimensional PMR Polyimide Composites Reinforced with Woven Basalt Fabric. Composites Part B: Engineering, 66, 268-275. https://doi.org/10.1016/j.compositesb.2014.05.028

[12] Zhang, Y., Xu, F., Zhang, C., Wang, J., Jia, Z., Hui, D., et al. (2016) Tensile and Interfacial Properties of Polyacrylonitrile-Based Carbon Fiber after Different Cryogenic Treated Condition. Composites Part B: Engineering, 99, 358-365. https://doi.org/10.1016/j.compositesb.2016.05.056

[13] Xu, F., Fan, W., Zhang, Y., Jia, Z., Qiu, Y. and Hui, D. (2017) Modification of Tensile, Wear and Interfacial Properties of Kevlar Fibers under Cryogenic Treatment. Composites Part B: Engineering, 116, 398-405. https://doi.org/10.1016/j.compositesb.2016.10.082

[14] Chou, T.-W. and Ko, F.K. (1989) Textile Structural Composites. Elsevier Science Publishers B V, Amsterdam.

[15] Boyina, D., Banerjee, A. and Velmurugan, R. (2014) Mixed-Mode Translaminar Fracture of Plain-Weave Composites. Composites Part B: Engineering, 60, 21-28. https://doi.org/10.1016/j.compositesb.2013.12.052

[16] Osada, T., Nakai, A. and Hamada, H. (2003) Initial Fracture Behavior of Satin Woven Fabric Composites. Composite Structures, 61, 333-339. https://doi.org/10.1016/S0263-8223(03)00058-8

[17] Nakai, A., Osada, T., Hamada, H. and Takeda, N. (2001) Role of Surface Treatment in Textile Composites. Composites Part A: Applied Science and Manufacturing, 32, 487-498. https://doi.org/10.1016/S1359-835X(00)00128-7 
[18] Xu, Z., Ichikawa, D. and Yang, Y. (2015) Initial Fracture Behavior of Intra CF/GF Woven Fabric Composites. ASME 2015 International Mechanical Engineering Congress and Exposition, American Society of Mechanical Engineers, V02BTA013-V02BT02A.

[19] Yu, B., Bradley, R., Soutis, C., Hogg, P. and Withers, P. (2015) 2D and 3D Imaging of Fatigue Failure Mechanisms of 3D Woven Composites. Composites Part A: Applied Science and Manufacturing, 77, 37-49. https://doi.org/10.1016/j.compositesa.2015.06.013

[20] Broutman, L. (1969) Measurement of the Fiber-Polymer Matrix Interfacial Strength. In: Interfaces in Composites, ASTM International.

[21] Lisle, T., Bouvet, C., Pastor, M.-L., Margueres, P. and Corral, R.P. (2013) Damage Analysis and Fracture Toughness Evaluation in a Thin Woven Composite Laminate under Static Tension using Infrared Thermography. Composites Part A: Applied Science and Manufacturing, 53, 75-87. https://doi.org/10.1016/j.compositesa.2013.06.004

[22] Green, S., Matveev, M., Long, A., Ivanov, D. and Hallett, S. (2014) Mechanical Modelling of 3D Woven Composites Considering Realistic Unit Cell Geometry. Composite Structures, 118, 284-293.

https://doi.org/10.1016/j.compstruct.2014.07.005

[23] Tan, P., Tong, L. and Steven, G. (1997) Modelling for Predicting the Mechanical Properties of Textile Composites-A Review. Composites Part A: Applied Science and Manufacturing, 28, 903-922. https://doi.org/10.1016/S1359-835X(97)00069-9

[24] Obert, E., Daghia, F., Ladeveze, P. and Ballere, L. (2014) Micro and Meso Modeling of Woven Composites: Transverse Cracking Kinetics and Homogenization. Composite Structures, 117, 212-221. https://doi.org/10.1016/j.compstruct.2014.06.035

[25] Carvelli, V., Corazza, C. and Poggi, C. (2008) Mechanical Modelling of Monofilament Technical Textiles. Computational Materials Science, 42, 679-691. https://doi.org/10.1016/j.commatsci.2007.10.003

[26] Siddiqui, M.O.R. and Sun, D. (2013) Finite Element Analysis of Thermal Conductivity and Thermal Resistance Behaviour of Woven Fabric. Computational Materials Science, 75, 45-51. https://doi.org/10.1016/j.commatsci.2013.04.003

[27] Kim, D.-H., Kim, H.-G. and Kim, H.-S. (2015) Design Optimization and Manufacture of Hybrid Glass/Carbon Fiber Reinforced Composite Bumper Beam for Automobile Vehicle. Composite Structures, 131, 742-752. https://doi.org/10.1016/j.compstruct.2015.06.028

[28] Mitchell, C., Dangora, L., Bielmeier, C. and Sherwood, J. (2016) Investigation into the Changes in Bending Stiffness of a Textile Reinforced Composite Due to In-Plane Fabric Shear: Part 1-Experiment. Composites Part A: Applied Science and Manufacturing, 85, 94-102. https://doi.org/10.1016/j.compositesa.2016.03.008

[29] Zako, M., Uetsuji, Y. and Kurashiki, T. (2003) Finite Element Analysis of Damaged Woven Fabric Composite Materials. Composites Science and Technology, 63, 507-516. https://doi.org/10.1016/S0266-3538(02)00211-7

[30] Boisse, P., Borr, M., Buet, K. and Cherouat, A. (1997) Finite Element Simulations of Textile Composite Forming Including the Biaxial Fabric Behaviour. Composites Part B: Engineering, 28, 453-464. https://doi.org/10.1016/S1359-8368(96)00067-4

[31] Boisse, P., Zouari, B. and Daniel, J.-L. (2006) Importance of In-Plane Shear Rigidity in Finite Element Analyses of Woven Fabric Composite Preforming. Composites Part A: Applied Science and Manufacturing, 37, 2201-2212.

https://doi.org/10.1016/j.compositesa.2005.09.018 
[32] Le Page, B., Guild, F., Ogin, S. and Smith, P. (2004) Finite Element Simulation of Woven Fabric Composites. Composites Part A: Applied Science and Manufacturing, 35, 861-872. https://doi.org/10.1016/j.compositesa.2004.01.017

[33] Madie, M., Mahdi, E. and Hamouda, A. (2011) An Investigation into Hybrid Carbon/Glass Fiber Reinforced Epoxy Composite Automotive Drive Shaft. Materials \& Design, 32, 1485-1500. https://doi.org/10.1016/j.matdes.2010.08.042

[34] Tabiei, A. and Jiang, Y. (1999) Woven Fabric Composite Material Model with Material Nonlinearity for Nonlinear Finite Element Simulation. International Journal of Solids and Structures, 36, 2757-2771. https://doi.org/10.1016/S0020-7683(98)00127-9

[35] Ichihashi, H., Hamada, H., Ikuta, N. and Maekawa, Z. (1994) Finite Element Analysis of Woven Fabric Composites Considering Interfacial Properties. Composite Interfaces, 2, 81-94. 